\title{
Significant improvements of acne after treatment with homeopathic medicines
}

\author{
Swami Shraddhamayananda* and AK Pradhan \\ Ramakrishna Mission Medical Unit, Belur Math, Howrah, West Bengal, India
}

\begin{abstract}
Acne is a common disease of the teenage population causing cosmetic disfigurements as well as many psychological problems in the affected persons. The main pathogenesis of the disease is the involvements of the oil glands at the base of hair follicles. The clinical lesions are usually papules and pustules over face, forehead, chest and back. In many cases, conventional treatment fails and the patients become helpless in this condition. Thus, in this study a possible curative role of homeopathic medicines was explored in such cases based on a pilot study done earlier at our Institute. A group of 400 such cases were enrolled in the study after consideration of all ethical issues and following inclusion and exclusion criteria formulated at our Institute. There were also a control group of 30 cases, where only placebo was given which were similar in appearance containing only vehicle of the medicine. Only a single oral homeopathic medicine out of two medicines "sulphur" or "tuberculinum" was given in the test group based on clinical case history as observed in the pilot study. No local application was used in the study. Out of 400 cases 387 (96.75\%) cases showed significant improvements within 6 months of treatment including cure in many cases within 3 months. The control group showed no changes even after 6 months. The results indicate a promising role of homeopathic medicines in such difficult cases.
\end{abstract}

\section{Introduction}

Acne vulgaris, a disease commonly occurs in adolescents is a chronic inflammatory disease characterized by formation of comedones, papules, pustules, cysts, nodules and even in some cases it leads to scar formation. Although in many cases it is very difficult to find the exact etiology of this disease, but it is often associated with follicular hyperkeratosis, hyper secretion of sebaceous glands, Propionibacterium acnes colonization, hypersensitivity and chronic inflammatory reactions. In general, hormones e.g., excess secretion of androgen; as it stimulates the oil gland and increased sebum secretion and progesterone which also increases sebum secretion while estrogen reduces it, but the vast majority, patients with acne have normal endocrine profile; excessive sebum, that can breakdown cellular wall causing bacteria to grow (Propionibacteria); hereditary/genetic factors e.g., a positive family history in many cases are commonly found. In our clinic $5 \%$ cases have positive family history. In some cases, conventional medicines like lithium; and pregnancy because of hormonal change are also blamed for development of acne.

Acne commonly affects face, anterior chest, and upper part of back [1]. Its prevalence in students above 10 years of age varies between 16.33-27.2\% and in adolescents it varies between $28.9-93.3 \%$ [2-7]. It usually begins in the teen age years (between 12 and 18 years) and lasts for 5-10 years. It may persist in adulthood (beyond 30 years). Male and female are equally affected. High glycaemic load diet and milk products may be important exciting factors. Different types of acne are given in Table 1. Differential Diagnosis of acne should be done with keratosis pillaris, rosacea and chloracne.

Conventional treatment of acne is usually done with resorcinol, benzyl peroxide, salicylic acid, sulphur, retin-A, antibiotics like erythromycin, oxytetracycline etc. Hormonal and laser therapy are done in selected cases. Though the conventional method of treatment gives relief to the patients of acne but it is expensive and patients suffer for a long time and often not without complications. Most of the patients in this study came after prolonged conventional treatment (6 months to 3 years) without any significant benefit. Considering all the above-mentioned facts, we treated these patients with homeopathic medicines which are alternative medicines without any side effects as these medicines are used in ultra-diluted forms and as homeopathic pharmacopoeia is approved in many nations/countries including India where this study was made and medicines are available in India over the counters easily and this method of treatment is accepted by the patients very easily. Details of homeopathy and medicines used in homeopathic practice are available elsewhere.

(http://en.wikipedia.org/wiki/Homeopathy; https://abchomeopathy. com/taking.htm )

\section{Pathogenesis of acne}

Pathogenesis of acne is not well understood. There are multiple

Table 1. Types of acne.

\begin{tabular}{|l|l|}
\hline Inflammatory & Non-Inflammatory \\
\hline Papules (pinheads) & Open comedones (Black heads) \\
\hline Pustules (pimples) & Closed comedones (white heads). \\
\hline Nodules (cyst) & \\
\hline Excorice (eroded papule) & \\
\hline
\end{tabular}

Correspondence to: Swami Shraddhamayananda, Ramakrishna Mission Medical Unit, Belur Math, Howrah, West Bengal, India, Tel:91-9143415986; E-mail: gopalmj.belurmath@gmail.com

Received: November 14, 2016; Accepted: December 07, 2016; Published: December 30, 2016 
factors like excess sebum production, androgen activity, bacterial colonisation, alteration of quality of sebum lipids and follicular hyperkeratinization etc. may responsible for this changes. These leads to erythema, hyperpigmentation, atrophic and hypertrophic changes.

\section{Materials and methods}

\section{The patients}

Total 400 patients were enrolled in this study. There were also 30 control cases those were given placebo and followed for two months to see if there was any change. Most of them aged between 13 to 22 years $(78 \%)$, their mean age was 18 years. Beyond 40 years of age there was only few female patients ( $2 \%$ of total patients). Age distribution of patients is given in Figure 5. Male: Female ratio was 1: 1. All patients were diagnosed, categorized, and followed up by our dermatologist of the Institution. The patients were enrolled after taking consent from the patients or from their parents. Permission of this study was also taken from Ethical committee of the Institute. Multiple open come done (non-inflammatory), multiple closed comedones, papule, and pustule (with moderate inflammation), multiple pustules and cysts (in inflammatory acne), severe inflammatory acne on forehead/central forehead/ nose/ chin - all these varieties of patients were treated. As most of the patients came after prolonged conventional treatment so in most of the cases all types of comedones were observed. In most of the cases face was commonly involved and although in 224 cases the patients could not remember the age of onset, among remaining 176 cases the age of onset was in between 14-17 years (Table 2 and Figure 6).

\section{Homoeopathic medicines and treatment}

The same medicines were given to all the patients except in the control group where only lactose pills were given which looks similar to our medicines and lactose was the vehicle of these medicines. The medicine was purchased from reputed homeopathic medicine shop (HAPCO) in Kolkata. In the placebo group there were 15 males and 15 females. Random selection was done of both sexes, of different casts and ages. Medicines were given as 4 pills (one dose) daily for 7 days then one dose in 15 days intervals. Only single oral homeopathic medicine (either "Sulphur" or "Tuberculinum") were used orally without any local application.

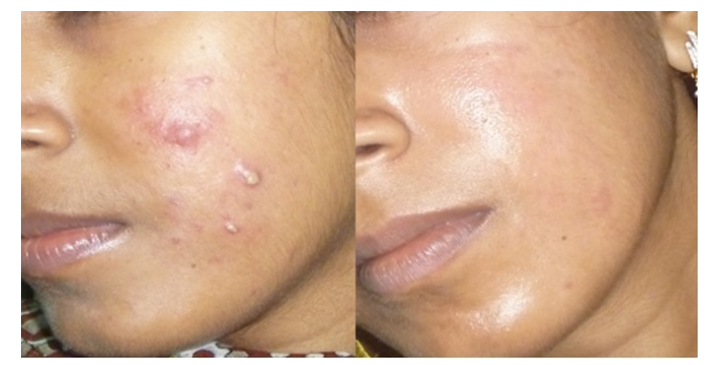

Figure 1. Acne with severe infection and sinus.

Table 2. Number and percentage of patients with acne, regarding affected area and age of onset.

\begin{tabular}{|l|l|}
\hline Area & Age of onset \\
\hline Face $(384,96.0 \%)$ & $\leq 9$ years $(16$ cases $)$ \\
\hline Face and trunk $(12,3.0 \%)$ & 10 years $(16$ cases $)$ \\
\hline Trunk $(4,1.0 \%)$ & 11 years $(24$ cases $)$ \\
\hline & 12 years $(20$ cases $)$ \\
\hline & 13 years $(20$ cases $)$ \\
\hline & $14-17$ years $(80$ cases $)$ \\
\hline & Not known $(224$ cases $)$ \\
\hline
\end{tabular}

\section{Results and discussion}

Earliest response was seen in majority number cases after 7 days and 387 patients were improved within 3 months. No response was noticed in 13 cases after 6 months of treatment. After two years follow up we have seen relapse in 16 cases. In placebo cases after 2 months follow up, out of 30 patients eruptions were increased in 18 patients and no change occurred in remaining 12 patients. Details of the results are given in Table 3 and in Figures 1-4 (Before and after treatment). This study indicated a definite role of homeopathic medicines in the treatment of acne, not only come done but also against inflammatory

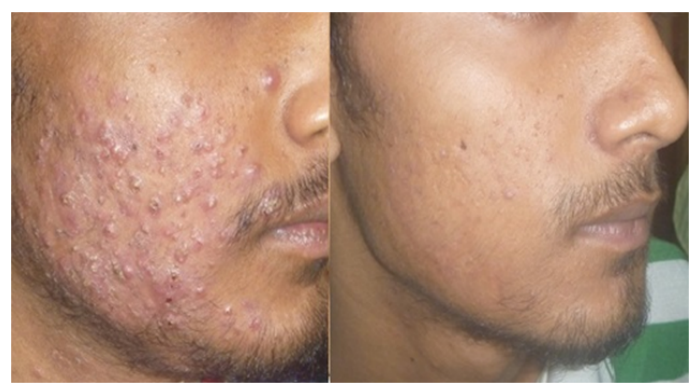

Figure 2. Severe acne vulgaris with cystic changes.

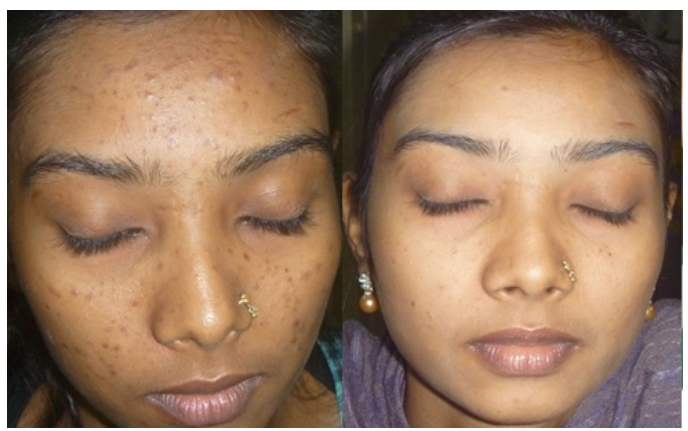

Figure 3. Acne with hyperpigmentation.

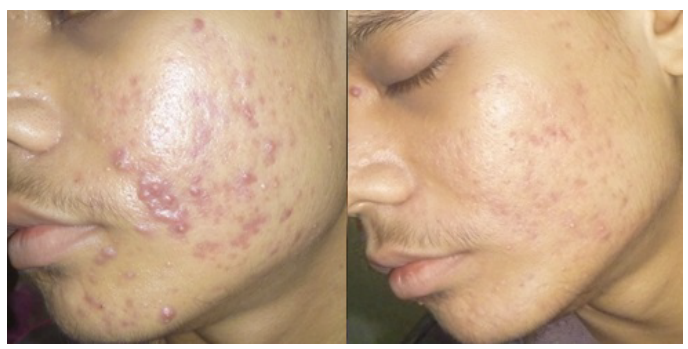

Figure 4. Repeated Acne with cystic changes.

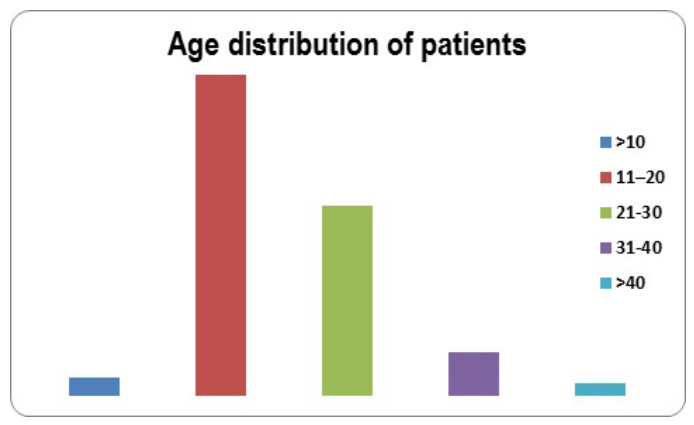

Figure 5. Age distribution of acne cases. 
Table 3. Acne according to severity and their outcome of treatment

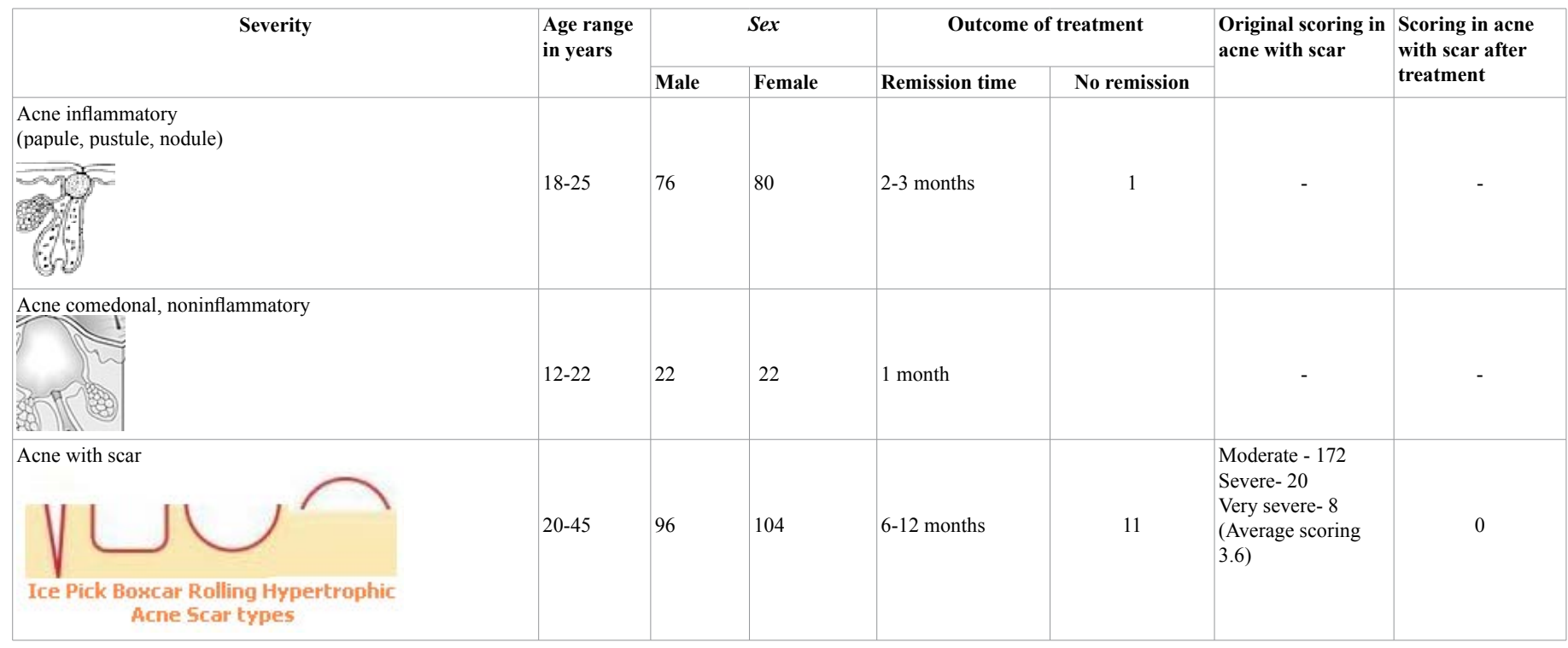

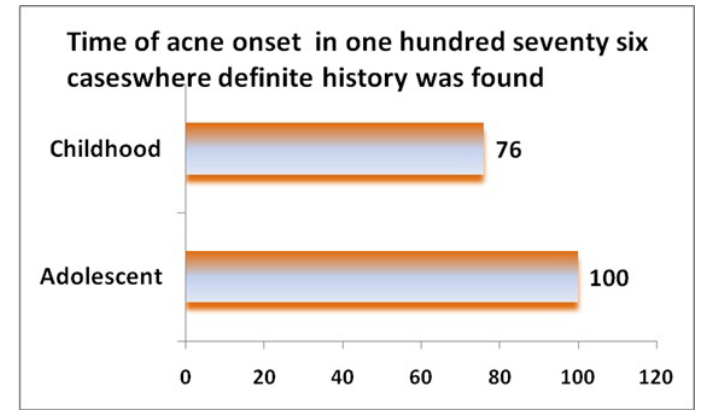

Figure 6. Graph showing onset time of acne.

acne cases. Probably the most interesting finding in this study is remission of acne associated with scars. The average scoring of 3.6 of the scar associated acne became zero scoring after the treatment. The real mechanism of action of these homeopathic medicines is very difficult to explain and so far, there is no definite explanation of the mechanism of action of these medicines. Thus possible attempts should be made in future studies to find out the mechanism. This preliminary report may help the suffering humanity at large.

\section{References}

1. Shen Y, Wang T, Zhou C, Wang X, Ding X, et al. (2012) Prevalence of acne vulgaris in Chinese adolescents and adults: a community-based study of 17,345 subjects in six cities. Acta Derm Venereol 92: 40-44. [Crossref]

2. Kilkenny M, Merlin K, Plunkett A, Marks R (1998) The prevalence of common skin conditions in Australian school students: 3. acne vulgaris. Br J Dermatol 139: 840-845. [Crossref]

3. Cunliffe WJ, Gould DJ (1979) Prevalence of facial acne vulgaris in late adolescence and in adults. $\mathrm{Br}$ Med $J$ 1: 1109-1110. [Crossref]

4. Smithard A, Glazebrook C, Williams HC (2001) Acne prevalence, knowledge about acne and psychological morbidity in mid-adolescence: a community-based study. $B r J$ Dermatol 145: 274-279. [Crossref]

5. Goulden V, Stables GI, Cunliffe WJ (1999) Prevalence of facial acne in adults. $J$ Am Acad Dermatol 41: 577-580. [Crossref]

6. Dréno B (2010) Recent data on epidemiology of acne. Ann Dermatol Venereol 137 Suppl 2: S49-51. [Crossref]

7. Law MP, Chuh AA, Lee A, Molinari N (2010) Acne prevalence and beyond: acne disability and its predictive factors among Chinese late adolescents in Hong Kong. Clin Exp Dermatol 35: 16-21. [Crossref]

Copyright: (C2016 Shraddhamayananda S. This is an open-access article distributed under the terms of the Creative Commons Attribution License, which permits unrestricted use, distribution, and reproduction in any medium, provided the original author and source are credited. 